\title{
A Functional Cyclic AMP Response Element Plays a Crucial Role in Neuroendocrine Cell Type-specific Expression of the Secretory Granule Protein Chromogranin A
}

Hongjiang Wu, Sushil K. Mahata, Manjula Mahata, Nicholas J. G. Webster, Robert J. Parmer, and Daniel T. O’Connor The Department of Medicine and Center for Molecular Genetics, University of California, San Diego; and the Department of Veterans Affairs Medical Center, San Diego, California 92161

\section{Abstract}

Chromogranin A, a soluble acidic protein, is a ubiquitous component of secretory vesicles throughout the neuroendocrine system. We reported previously the cloning and initial characterization of the mouse chromogranin A gene promoter, which showed that the promoter contains both positive and negative domains and that a proximal promoter spanning nucleotides -147 to +42 bp relative to the transcriptional start site is sufficient for neuroendocrine cell type-specific expression. The current study was undertaken to identify the particular elements within this proximal promoter that control tissue-specific expression. We found that deletion or point mutations in the potential cAMP response element (CRE) site at -68 bp virtually abolished promoter activity specifically in neuroendocrine (PC12 chromaffin or AtT20 corticotrope) cells, with little effect on activity in control (NIH3T3 fibroblast) cells; thus, the CRE box is necessary for neuroendocrine cell type-specific activity of the chromogranin A promoter. Furthermore, the effect of the CRE site is enhanced in the context of intact (wild-type) promoter sequences between -147 and -100 bp. DNase I footprint analysis showed that these regions (including the CRE box) bind nuclear proteins present in both neuroendocrine (AtT20) and control (NIH3T3) cells. In AtT20 cells, electrophoretic mobility shift assays and factor-specific antibody supershifts showed that an oligonucleotide containing the chromogranin A CRE site formed a single, homogeneous protein-DNA complex containing the CRE-binding protein CREB. However, in control NIH3T3 cells we found evidence for an additional immunologically unrelated protein in this complex. A single copy of this oligonucleotide was able to confer neuroendocrine-specific expression to a heterologous (thymidine kinase) promoter, albeit with less fold selectivity than the full proximal chromogranin A promoter. Hence, the CRE site was partially sufficient to explain the neuroendocrine cell type specificity of the promoter. The functional activity of the CRE site was confirmed through studies of the endogenous chromogranin A gene. Northern mRNA analysis showed that expression of the endogenous chromogranin A gene was stimulated seven- to eightfold by cAMP in PC12 cells, whereas no induction occurred in the

Address correspondence to Dr. Daniel T. O'Connor, Department of Medicine $(9111 \mathrm{H})$, University of California, San Diego, 3350 La Jolla Village Drive, San Diego, CA 92161-9111H. Phone: 619-5528585×7373, FAX: 619-552-8585×7372; E-mail: doconnor @ucsd.edu

Received for publication 29 November 1994 and accepted in revised for 23 March 1995.

The Journal of Clinical Investigation, Inc.

Volume 96, July 1995, 568-578
NIH3T3 cells. Similar cAMP induction was obtained with the transfected chromogranin A promoter in PC12 cells, and abolition of the CRE site (by deletion or point mutation) eliminated the induction. Thus, the CRE site in the chromogranin A proximal promoter is functional and plays a crucial, indeed indispensable, role in neuroendocrine-specific expression of the gene. These results also provide insight into transcriptional mechanisms governing acquisition of the neuroendocrine secretory phenotype. (J. Clin. Invest. 1995. 96:568-578.) Key words: Chromogranin A • PC12 • AtT20 • cyclic AMP • promoter

\section{Introduction}

The chromogranins/secretogranins are a family of soluble, acidic proteins present as the major constituents in secretory vesicle cores of virtually all neuroendocrine tissues [1-3]. The most widely expressed of this protein family is the $48-\mathrm{kD}$ chromogranin A (4).

We previously isolated a functional transcriptional promoter from the mouse chromogranin A gene and characterized its expression in neuroendocrine versus control cells (5). Our results suggested that the $5^{\prime}$ flanking region of the chromogranin A gene contains multiple functional transcriptional regulatory elements, both positive and negative, which behave largely as promoter rather than enhancer domains (5). Using deletion mutagenesis, we localized a proximal promoter (which conferred neuroendocrine-specific expression) to a region spanning nucleotides -147 to +42 bp relative to the transcriptional start site. Further deletion to -77 bp retained neuroendocrine-specific expression, whereas deletion to $-61 \mathrm{bp}$ abolished cell type-specific promoter activity. A comparison of the mouse chromogranin A proximal promoter region sequence with the rat (5), bovine (6), and human (7) chromogranin A promoters showed high conservation of overall promoter structure. Each species' promoter contains a cAMP/response element (CRE) ${ }^{1}$ consensus sequence (10) upstream of a TATA box. Two other members of this family of proteins, chromogranin B and secretogranin II (also known as chromogranin C), contain similar CRE and TATA homologies in their proximal gene promoters $(8,9)$.

However, the proximal chromogranin A promoter contains numerous structural matches to potential cis elements other than the CRE box (10), and even the functional importance of the CRE homology in this promoter region remains unexplored. In the current study, we analyzed the proximal chromogranin A promoter $(-147$ to $-48 \mathrm{bp})$ by scanning mutagenesis at high

1. Abbreviations used: CMV, cytomegalovirus; CRE, cAMP responsive element; CREB, CRE-binding protein; CREM, CRE modulator protein; DBH, dopamine $\beta$-hydroxylase; LUC, luciferase; TK, thymidine kinase. 


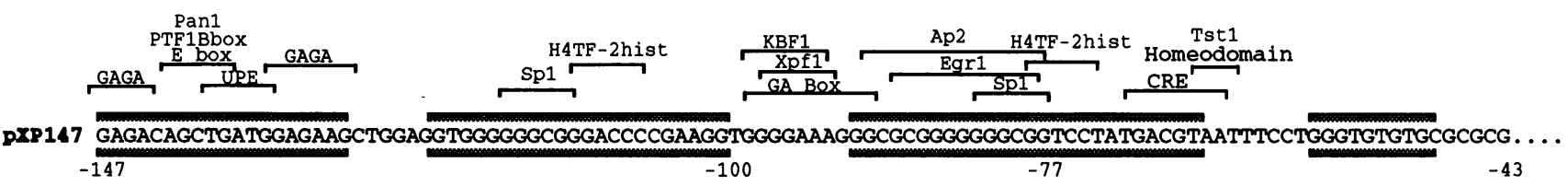

M32 GAGAศtCCACATGGAGAAGCTGGAGGTGGGGGCGGGACCCCGAAGGTGGGAAAGGGCGCGGGGGGCGGTCCTATGACGTAATTTCCTGGGTGTGTGCGCGCG. .. .

M33 GAGACAGCTGLAGGAGAAGCTGGAGGTGGGGGGCGGGACCCCGAAGGTGGGGAAAGGGCGCGGGGGGGCGGTCCTATGACGTAATTTCCTGGGTGTGTGCGCGCG. . . M34 GAGACAGCTGATGAtot AGCTGGAGGTGGGGGGGGGACCCCGAAGGTGGGGAAAGGGCGCGGGGGGCGGTCCTATGACGTAATTTCCTGGGTGTGTGCGCGCG. . . M35 GAGACAGCTGATGGAGAAGCTGGAGGTGGGE_ELEGGACCCCGAAGGTGGGGAAAGGGCGCGGGGGGGCGGTCCTATGACGTAATTTCCTGGGTGTGTGCGCGCG. .. . M36 GAGACAGCTGATGGAGAAGCTGGAGGTGGGGGCGGGACCC ЕCTAGTGGGGAAAGGGCGCGGGGGGCGGTCCTATGACGTAATTTCCTGGGTGTGTGCGCGCG. .. . $-100$ 




Figure 2. 5' deletion mutants of the chromogranin A proximal promoter. Promoter deletions were performed as described in Methods and inserted into the promoterless luciferase reporter vector $\mathrm{pXP1}$. The promoter deletion/luciferase reporter constructs were transfected into neuroendocrine ( $\mathrm{PC} 12$ chromaffin or AtT20 corticotrope) or control (NIH3T3 fibroblast) cells, along with the transfection control efficiency plasmid CMV-lacZ. The results are expressed as ratios of luciferase $/ \beta$-galactosidase activities. The pXP100 data amplify the previously reported (5) series of deletion mutants. activity (18), and $\beta$-galactosidase activity (17). To control for differences in transfection efficiency among cell lines and plasmids, co-transfections were performed with 0.4-0.8 $\mu \mathrm{g}$ of CMV-lacZ (Clontech, Palo Alto, CA), encoding $\beta$-galactosidase controlled by the cytomegalovirus (CMV) promoter. Luciferase results were normalized to $\beta$-galactosidase activity.

To test functional activation of the CRE in the promoter, the transfected cells were cultured for 4 or $24 \mathrm{~h}$ after transfection in the presence of $1 \mathrm{mM}$ dibutyryl cAMP and/or 0.1 and $0.5 \mu \mathrm{M}$ protein kinase A-specific inhibitor KT5720 before harvesting.

In vitro binding studies. Double-stranded oligonucleotides spanning the CRE region -76 to $-59 \mathrm{bp}$ were synthesized, labeled by filling in $5^{\prime}$ overhangs with $\left.{ }^{32} \mathrm{P}\right] \mathrm{dCTP}$ and the Klenow fragment of $E$. coli DNA polymerase I, and used in electrophoretic mobility shift assays with nuclear extracts from AtT20 or NIH3T3 cells. Nuclear extracts were prepared as described (19). Labeled fragments $\left(10^{5} \mathrm{dpm}, \sim 0.15 \mathrm{pmol}\right)$ were incubated with nuclear extracts $(2 \mu \mathrm{g}$ of protein) in the presence of poly $(\mathrm{dl} \cdot \mathrm{dC})(0.2 \mu \mathrm{g} / \mathrm{ml})$ as nonspecific competitor. Bound and free DNA were separated by electrophoresis through $5 \%$ acrylamide $/ 0.4 \times$ TBE gels (19), which were dried and subjected to autoradiography at $-70^{\circ} \mathrm{C}$. In some experiments, the binding of pure (recombinant) CREB was used as a positive control, and a polyclonal antipeptide antibody raised against a synthetic peptide containing amino acids 121-159 (the kinase-inducible domain) of rat CREB (12) was used to supershift the protein-DNA complex. DNase I footprinting was performed as described previously (5).

Northern blot analysis of $m R N A$. PC12 and NIH3T3 cells were treated with dibutyryl cAMP $(1 \mathrm{mM})$ for $1,4,6$, and $24 \mathrm{~h}$, with or without the addition to the protein kinase A-specific inhibitor KT4720 $\left(10^{-7}\right.$ or $\left.5 \times 10^{-7} \mathrm{M}\right)$ or cycloheximide $(5 \mu \mathrm{g} / \mathrm{ml})$. Treatment of these cells with $5 \mathrm{gmg} / \mathrm{ml}$ cycloheximide decreases incorporation of $\left.{ }^{35} \mathrm{~S}\right]$ methionine into TCA-precipitable protein by $>95 \%(20)$. Total RNA was isolated by acid guanidinium thiocyanate-phenol-chloroform extraction (RNAzolB; TelTest, Friendswood, TX). RNAs (10 $\mu \mathrm{g})$ were size fractionated on denaturing $1 \%$ agarose-formaldehyde gels, transferred to nitrocellulose membranes, and fixed with ultraviolet irradiation (StrataLinker; Stratagene, La Jolla, CA). The blots were prehybridized, hybridized, and washed essentially as described previously (17). Hybridization was performed separately with either a ${ }^{32} \mathrm{P}$-labeled mouse chromogranin A cDNA probe (21), or a rat cyclophilin ("housekeeping") cDNA probe (22). Expression of chromogranin A mRNA was quantified using a StrataScan 7000 densitometer (Stratagene) and normalized to cyclophilin gene expression.

Data presentation. Transfection experiments were repeated three times, with three plates per condition per experiment. Results are shown on bar graphs as the mean value for separate transfections \pm 1 SD.

\section{Results}

Site-directed, dense scanning mutation analysis of the chromogranin A proximal promoter. We demonstrated previously that the region from -147 to +42 bp relative to the transcriptional initiation (cap) site was sufficient to direct neuroendocrine-specific expression of the chromogranin A promoter (5). High levels of expression after transfection were observed in the neuroendocrine cell lines PC12 (rat adrenal medullary chromaffin cell), AtT20 (mouse anterior pituitary corticotrope), and GH3 (rat anterior pituitary somatolactotrope). By contrast, tranfected NIH3T3 fibroblast and COS monkey kidney cells, the nonendocrine cell lines, showed low levels of luciferase activity. To define the promoter elements responsible for neuroendocrine expression, additional $5^{\prime}$ promoter deletions were constructed and transiently transfected into NIH3T3, AtT20, and PC12 cells as described previously (Fig. 1). In AtT20 and PC12 cells, deletion from -147 to -100 or -77 bp diminished reporter expression by $\sim 50 \%$, but had no effect in NIH3T3 cells (Fig. 2). Further deletion to -61 bp eliminated all cell type specificity.

A dense series of scanning site-directed mutants was created to localize more closely the promoter element(s) necessary for neuroendocrine cell type-specific expression (Fig. 1). The mutants were tested by transfection into the PC12, AtT20, and NIH3T3 cell lines as has been described. The first set of 16 mutants are derived from pXP100 (Figs. 1 and 3). The defined mutations cover the region between -97 and $-48 \mathrm{bp}$, since there are a number of potential transcription factor-binding sites here (5) and we had previously identified DNase I footprints in this region using AtT20 nuclear extracts (5). Mutations in the region -100 to -74 bp (Fig. 3; mutants M2-M8) had only a modest effect on promoter activity in all three cell lines, especially mutants M4-M9. This is consistent with our earlier results (5) that deletion to -77 bp maintained tissue-specific expression (Fig. 2). Similarity, mutations in the region -54 to $-48 \mathrm{bp}$ had no effect on promoter activity in all three cell lines (Fig. 3; mutants M21 and M22). However, mutations between -77 and $-54 \mathrm{bp}$ had a profound effect on promoter activity (Fig. 3; mutants M9-M19). In particular, mutations in a CRElike sequence from -71 to -64 bp reduced promoter activity by $95 \%$ in PC12 and AtT20 cells (Fig. 3; mutants M12, M13, 




Figure 3. Effect of dense scanning site-directed mutants on chromogranin A promoter expression. The mutant plasmids (mutations M2M22; for explanations and other symbols see the legend to Fig. 1) and their control (pXP100) were transfected into neuroendocrine ( $\mathrm{PC1} 2$ or AtT20) or control (NIH3T3 fibroblast) cells and processed for luciferase and $\beta$ galactosidase reporter assay. The results were normalized to pXP100 and expressed as percent luciferase activity. and M15). These mutations were less severe in NIH3T3 cells, but still caused $30-60 \%$ declines in promoter activity. Mutation of the chromogranin A CRE-like sequence to a consensus CRE site (mutant M14) caused a 50-80\% increase in promoter activity over the corresponding wild-type sequence (in pXP100) in all three cell types, underscoring the importance of this sequence (Fig. 3).

The importance of the CRE-like sequence for neuroendocrine-specific expression was further confirmed by introduction of the M12 mutation into pXP77 (Fig. 4), which is the smallest 5 ' deletion mutant ( $-77 \mathrm{bp}$ ) that maintains tissue-specific expression. As before, this mutation cause a $>90 \%$ loss of activity in AtT20 and PC12 cells, but only a 50\% loss in 3T3 cells (Fig. 4; mutant M41).

A second set of scanning mutations was created between -147 and $-100 \mathrm{bp}$ in plasmid pXP147 (Fig. 5). We noticed previously (Fig. 2) that deletion of this region caused a $\sim 50 \%$ decline in promoter activity in PC12 and AtT20 cells, but had no effect on expression in NIH3T3 cells, suggesting that the -147 to $-100 \mathrm{bp}$ region may potentiate the action of the major tissue-specific element located between -77 and $-61 \mathrm{bp}$. These mutants (M32-M36) were transfected into the three cell lines as previously described. None of the mutations affected promoter activity in AtT20 or NIH3T3 cells, but two mutations (M35 and M36) selectively decreased promoter activity by $\sim 60 \%$ in PC12 cells (Fig. 5). The lack of effect in AtT20 cells may indicate a redundancy of sites in this region, such that mutations of a single site is not detrimental in the AtT20 nuclear milieu; however, deletion of the entire -147 to -100 bp region reduces activity by $\sim 50 \%$.

In vitro binding of neuroendocrine nuclear proteins to the potential CRE site in the proximal promoter. We reported previously (5) that nuclear extracts from AtT20 corticotropes protected several regions of the chromogranin A proximal promoter from DNase I digestion (summarized in Fig. 1). Since the CRElike sequence appears to be so important from the mutagenesis studies (Figs. 3 and 4), we compared the binding of AtT20 and NIH3T3 nuclear extracts with this region. The DNase I footprint with the NIH3T3 extract was similar to that with the AtT20 extract (Fig. 6); each footprint spanned -66 to -91 bp. The most obvious quantitative difference is the very strong induction of a DNase I-hypersensitive site at -64 bp (Fig. 6). This site is indicative of protein binding to this region.

To analyze the footprinted region further, double-stranded oligonucleotide probes containing the chromogranin A (original) CRE site (TGACGTAA) were synthesized and end labeled with ${ }^{32} \mathrm{P}$ (Fig. 7). In addition, oligonucleotide probes were synthesized containing the M12 CRE mutation (TGA-GTAA) or a consensus (perfect) CRE (TGACGTCA). All three probes were used in gel retardation assays with either AtT20 and NIH3T3 extracts or purified CREB. Both the AtT20 and NIH3T3 extracts generated retarded complexes of the chromogranin A CRE oligonucleotide (Fig. 7, lanes 4 and 6). The mobility of the major complex was identical to the complex seen with purified CREB (Fig. 7, lane 2). The presence of CREB in these complexes in the AtT20 and NIH3T3 extracts was confirmed by using an anti-CREB antibody that caused a supershift of the complex (Fig. 7, lanes 3 and 5). The entire complex was supershifted by anti-CREB in AtT20 extracts, and only a single resulting supershifted complex was observed. However, only a portion of the NIH3T3 shifted complex was supershifted by anti-CREB, and two resulting supershifted complexes were observed.

Similar complexes were observed with the perfect consensus CRE sequence (Fig. 7, lanes 8 and 9). Introduction of the M12 mutation into the CRE (mutated CRE) abolished the AtT20 complexes and reduces the intensity of the NIH3T3 complex (Fig. 7, lanes 11 and 12). This mutation eliminated CREB 

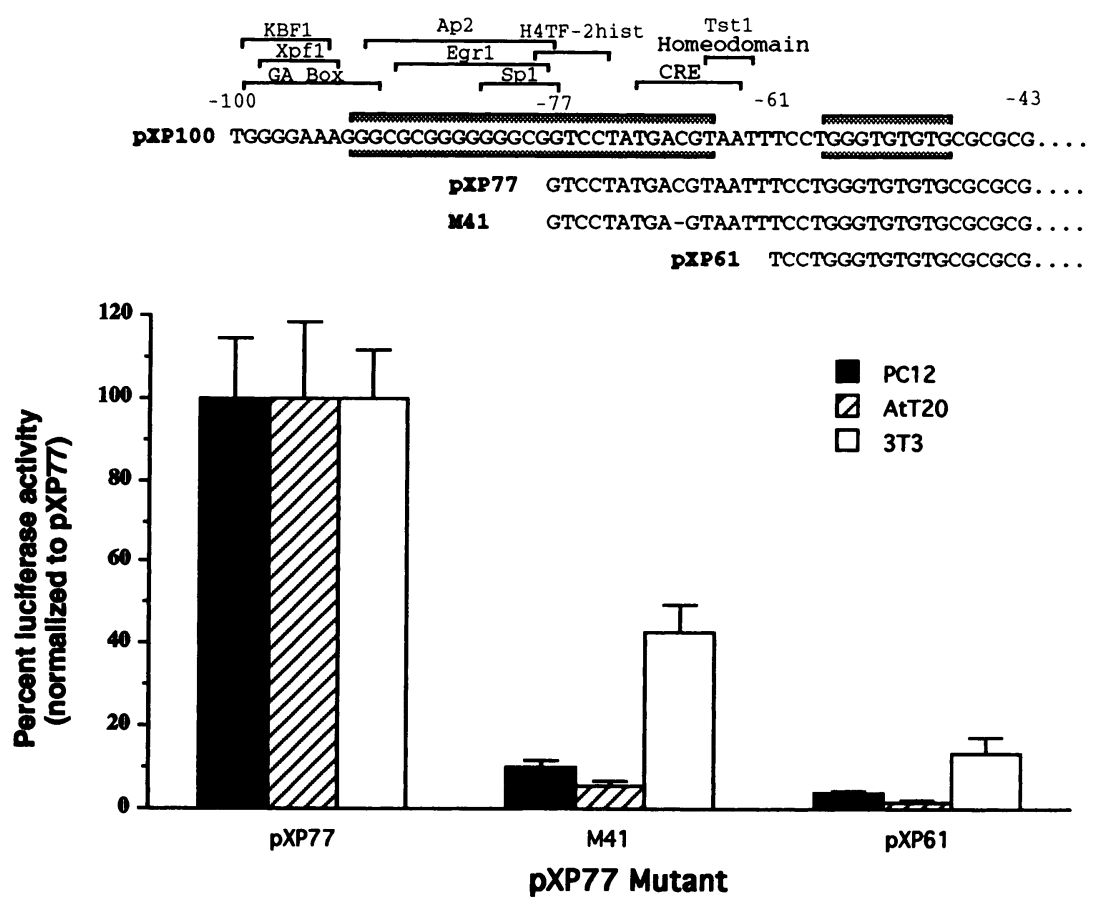

Figure 4. Mutation of the CRE site in the minimal promoter. The CRE mutant promoter plasmid (mutation M41; for explanations and other symbols, see the legend to Fig. 1) and its wild-type control (pXP77) or the further deletion mutant pXP61 were transfected into neuroendocrine (PC12 or AtT20) or control (NIH3T3 fibroblast) cells and processed for luciferase and $\beta$-galactosidase reporter assay. The results were normalized to pXP77 results and expressed as percent luciferase activity.

binding to the chromogranin A CRE and reduced the binding in the NIH3T3 extract, consistent with the loss of the CREBcontaining complexes. This mutation (from TGACGTAA to TGA-GTAA) creates an AP1 site (23) so the residual complex in the NIH3T3 extract may result from factors that recognize AP1 sites. In addition to the CREB complexes, there was another less abundant, higher (faster) mobility complex in the AtT20 and NIH3T3 extracts (Fig. 7, lanes 1, 3-6, 8, 9, 11, and 12). The origin of this complex is not known, but it is likely to be a nonspecific protein-DNA complex, sine a 50-fold excess of unlabeled CRE probe could not compete (Fig. 7, lane 1).
Stimulation of a heterologous promoter by a functional chromogranin A CRE promoter element in neuroendocrine versus control cells. To investigate further the function of the CRE site in chromogranin A expression, the CRE domains used in the gel retardation experiment were tested for ability to stimulate a neutral, heterologous TK promoter. A single copy of each variation of the chromogranin A CRE (the original [chromogranin A wild-type] CRE, the mutant [M12] CRE, and a perfect CRE) was cloned into PTK-LUC upstream of a minimal TK promoter (5). These promoter/reporter plasmids were transfected into AtT20, PC12, and NIH3T3 cells as has been described.

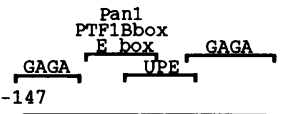

$-147$

pXP147 GAGACAGCTGATGGAGAAGCI

agtcCaca getgta

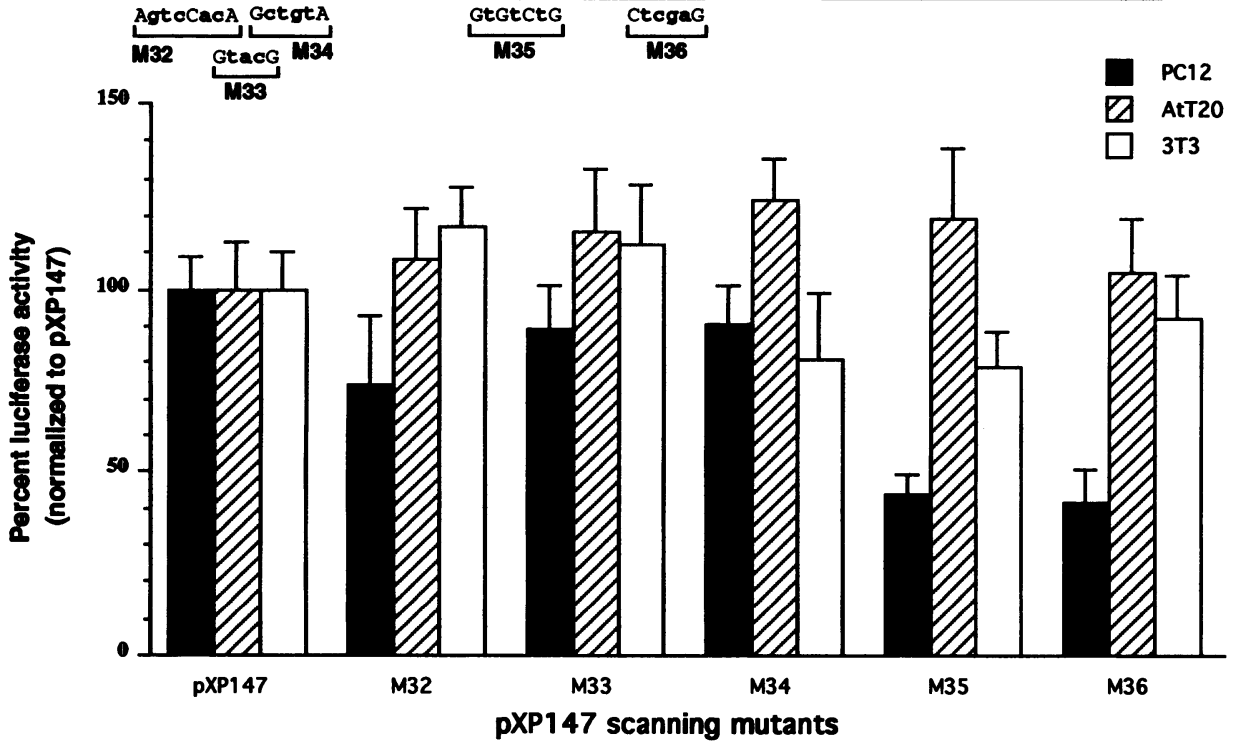

Figure 5. Importance of the region between -100 and $-147 \mathrm{bp}$ in the chromogranin A promoter. The promoter mutant plasmids (M32M36; for explanations and other symbols see the legend to Fig. 1) and their wild-type control (pXP147) were transfected into neuroendocrine (PC12 or AtT20) or control (NIH3T3 fibroblast) cells and processed for luciferase and $\beta$-galactosidase reporter assay. The results were normalized to pXP147 and expressed as percent luciferase activity. 


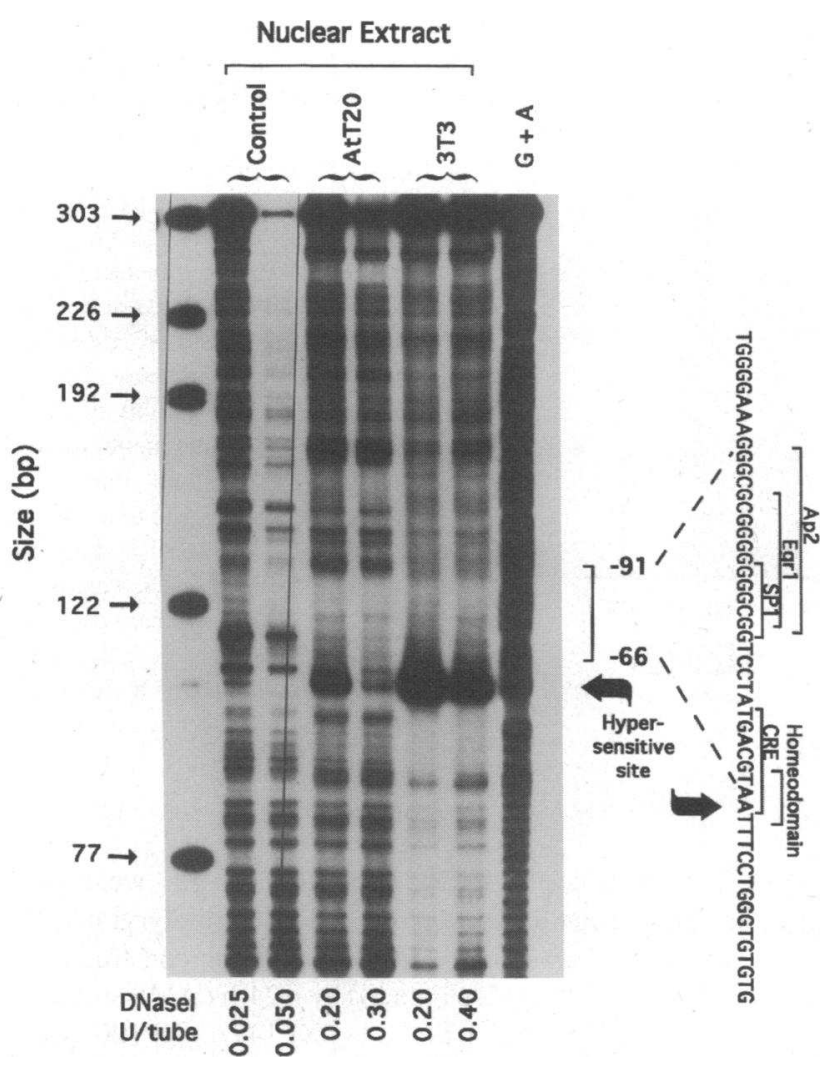

Figure 6. DNase footprinting of the chromogranin A proximal promoter. Promoter DNA templates, ${ }^{32} \mathrm{P}$-labeled at one end, were incubated with extracts ( $50 \mu \mathrm{g}$ of nuclear protein) of neuroendocrine (AtT20) or control (NIH3T3) nuclei, digested with DNase I, and subjected to polyacrylamide gel electrophoresis, followed by gel drying and autoradiography. The bracket indicates the area protected (footprinted) from DNase digestion by AtT20 and NIH3T3 nuclear proteins. The arrows indicate a site made hypersensitive to DNase I digestion by AtT20 and NIH3T3 nuclear proteins. Known transcription factor-binding sites are indicated by the legend directly above the sequence. AtT20, mouse anterior pituitary corticotrope cell line; $N I H 3 T 3$, mouse fibroblast cell line; $G+A$, purine size ladder from the Maxam-Gilbert sequencing reaction; Control, promoter DNA template not incubated with nuclear extract protein, before DNase I digestion. The results of AtT20 footprinting in this region have been reported previously (5).

The original minimal-promoter vector pTK-LUC was 2-fold less active in $\mathrm{PC} 12$ cells $(7.36 \pm 1.57$ luciferase units per $\beta$ galactosidase unit) and 10-fold less active in AtT20 cells $(1.41 \pm 0.11$ luciferase units per $\beta$-galactosidase unit) than in NIH3T3 fibroblasts ( $13.9 \pm 3.34$ luciferase units per $\beta$-galactosidase unit). Both the original and perfect (consensus) CRE insertions stimulated reporter expression by more than sevenfold in the PC12 and AtT20 cells, but were ineffective in the NIH3T3 cells (Fig. 8). As expected, the mutated chromogranin A CRE oligonucleotide did not augment TK promoter activity significantly in AtT20 or PC12 cells. However, mutation of the chromogranin A CRE (Fig. 8) did cause an approximately threefold selective elevation in reporter activity in NIH3T3 fibroblasts, perhaps because the mutant CRE (TGAGTAA) creates a potential match for the AP1 consensus site $(23,24)$.

Chromogranin A mRNA expression in response to cAMP. The importance of the CRE sequence in the tissue-specific expression of the chromogranin A promoter raises the notion that cAMP itself may induce the chromogranin A gene. Conse-

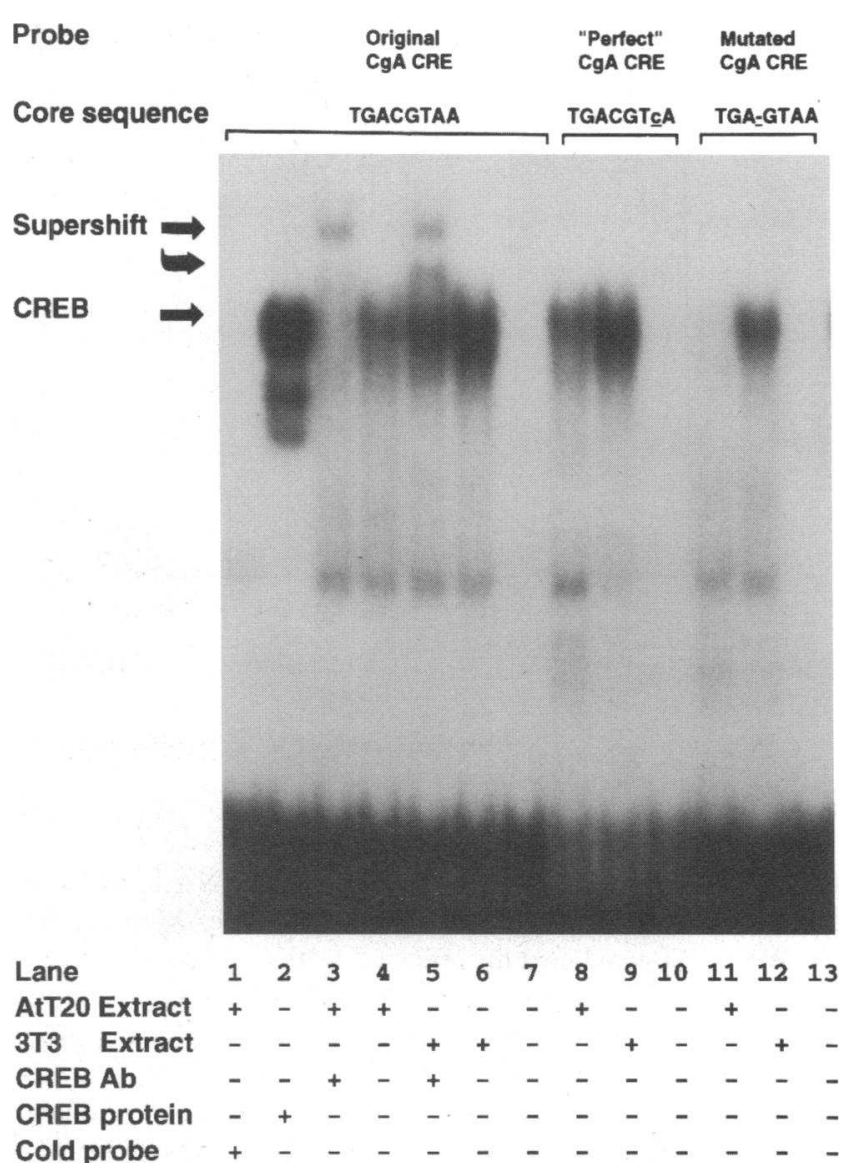

Figure 7. Electrophoretic mobility shift assay on the chromogranin A CRE. Double-stranded oligonucleotides spanning the chromogranin A $\mathrm{CRE}$ region ( -76 to $-59 \mathrm{bp}$ ) were synthesized and ${ }^{32} \mathrm{P}$ labeled by filling in 5' overhands with the Klenow fragment of DNA polymerase. Labeled fragments $\left(10^{5} / \mathrm{dpm}\right)$ were incubated either with nuclear extracts ( $2 \mu \mathrm{g}$ of protein) from neuroendocrine (AtT20) or control (NIH3T3) cells, or with purified CREB, with or without a 50-fold molar excess of cold (unlabeled) probe and then subjected to gel electrophoresis $(0.4 \times$ TBE gels), followed by autoradiography. Both the AtT20 (lane 4) and NIH3T3 (lane 6) extracts formed complexes with the chromogranin A CRE oligonucleotide. The mobility of the major complex is identical to that produced by pure CREB (lane 2). Note the occurrence of a single anti-CREB supershifted AtT20 CRE complex (lane 3), whereas distinctly different CRE complexes (one unshifted, one shifted to a greater [ faster] mobility) are seen after anti-CREB supershift with the NIH3T3 extract. Conversion of the original chromogranin A CRE (TGACGTAA) to a perfect CRE (as in mutant M14 [Figs. 1 and 3]) is indicated by the underlined and lowercase base in $T G A C G T \underline{c}$. The single base deletion mutation (as in mutants M12 [Figs. 1 and 3] and [Figs. 1, 4, and 11]) of the chromogranin A CRE is indicated by an underlined hyphen (TGA-GTAA).

quently, we tested whether the endogenous chromogranin A gene was stimulated by cAMP in PC12 and NIH3T3 cells. Cells were treated with dibutyryl cAMP for increasing periods of time, and the RNA was subjected to Northern analysis. Results of a representative experiment are shown in Fig. 9. Treatment of PC12 cells caused a 2.8-4.0-fold increase in chromogranin A mRNA by $4 \mathrm{~h}$. The increase was maximal by $6 \mathrm{~h}$ (6.7-7.9fold) and maintained at the elevated level for $24 \mathrm{~h}$ (7.0-8.4fold). Similar stimulation was seen with 8-bromo-cAMP. In contrast, cyclophilin mRNA showed no consistent increase after 


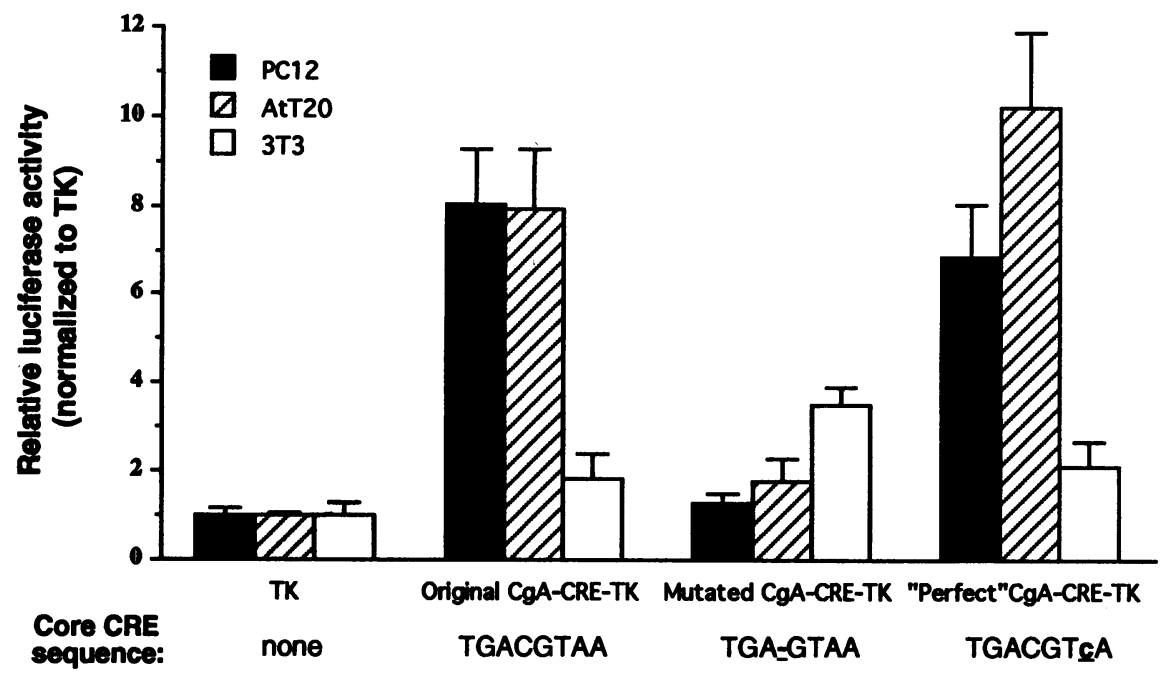

Synthetic CRE-TK luciferase reporters
Figure 8. Stimulation of a heterologous TK promoter by the chromogranin A CRE site. A single copy of a double-stranded synthetic chromogranin A CRE fragment and its mutants were cloned into the enhancerless promoter/luciferase reporter vector pTK-LUC, immediately upstream $\left(5^{\prime}\right)$ of the TK promoter. These plasmids were transfected into neuroendocrine (PC12 or AtT20) or control (NIH3T3 fibroblast) cells and processed for luciferase reporter and protein assay. The results were normalized to the activity of pTKLUC and expressed as relative luciferase activity. Conversion of the original chromogranin A CRE (TGACGTAA) to a perfect CRE (as in mutant M14 [Figs. 1 and 3]) as indicated by the underlined and lowercase base in TGACGT $\underline{c} A$. The single base deletion mutation (as in mutants M12 [Figs. 1 and 3] and M4 [Figs. 1, 4, and 11]) of the chromogranin A CRE is indicated by an underlined hyphen (TGA-GTAA).
cAMP (Figs. 9 and 10). Chromogranin A mRNA levels were undetectable in NIH3T3 cells, with or without cAMP (Fig. 9).

We investigated next the effect of protein synthesis (translation) inhibition or protein kinase $\mathrm{A}$ inhibition on the induction of chromogranin A gene by cAMP in PC12 cells (Fig. 10). Cycloheximide $(5 \mu \mathrm{g} / \mathrm{ml}$ ) was unable to prevent the 2.7-4.0fold induction at $4 \mathrm{~h}$ of cAMP. At later time points, cycloheximide decreased basal chromogranin A mRNA levels by $61-$ $70 \%$ and reduced the cAMP induction by $62-81 \%$. This indicates that new protein synthesis is required to account for the full magnitude of sustained elevation in chromogranin $A$ mRNA, consistent with the normal turnover of cAMP-responsive transcription factors, such as CREB itself $(12,13)$. The protein kinase A inhibitor KT5720 inhibited the cAMP induction, in an inhibitor dose-dependent fashion, confirming the role of protein kinase A (Fig 10). (11).

Clearly, prolonged $(24 \mathrm{~h}) 5 \mu \mathrm{g} / \mathrm{ml}$ cycloheximide diminishes overall cell growth and proliferation. However, our conclusions are drawn from Northern blot lanes (Fig. 10), in which constant amounts $(10 \mu \mathrm{g})$ of total RNA were loaded per lane, and the data were normalized to values of chromogranin $A$ mRNA/cyclophilin (housekeeping, control) mRNA signals.

cAMP stimulation of the transfected chromogranin A promoter. Since cAMP induced the endogenous chromogranin A gene in PC12 cells, we tested whether the transfected chro- mogranin A promoter/luciferase reporter plasmids were also inducible. Transfected cells were treated with dibutyryl cAMP for 4-24 $\mathrm{h}$ before harvesting. All of the deletion constructions from $-1.1 \mathrm{~kb}$ to $-77 \mathrm{bp}$ were induced by a 24-h cAMP stimulation (Fig. 11 pXP1133, pXP426, pXP147, pXP100, and pXP77). Slightly lower inductions (three- to fivefold) were obtained at $4 \mathrm{~h}$ with all the deletion mutants. Deletion to -61 $\mathrm{bp}$, as well as introduction of the single base pair CRE deletion (M41) in the shorter promoter fragment pXP77, eliminated the induction, consistent with removal of the cAMP-responsive sequence (Fig. 11; pXP61 and mutant M41). The involvement of protein kinase $\mathrm{A}$ in induction of the chromogranin A promoter by cAMP was confirmed using the protein kinase $A$ inhibitor KT5720. KT5720 $\left(10^{-7} \mathrm{M}\right)$ inhibited cAMP induction of either pXP100 or pXP77 by $\sim 40 \%$ (data not shown).

\section{Discussion}

Deletion analysis and site-directed mutagenesis of the proximal chromogranin A promoter ( -147 to +42 bp) have demonstrated that a CRE-like sequence is crucial for neuroendocrinespecific promoter activity (Figs. 2, 3, and 4). This CRE sequence is also able to mediate an 8-fold induction of the transfected chromogranin A promoter by cAMP (Fig. 11), which is similar in magnitude to the 7.0-8.4-fold induction of
PC12 cells

Chromogranin A (Cg
Cyclophilin (Cph)
db-cAMP treatment
(1mM), time (hours)

(1mM), time (hours)

\section{Relative CgA expression} (normalized to $\mathrm{Cph}$ )

\section{T3 cells}

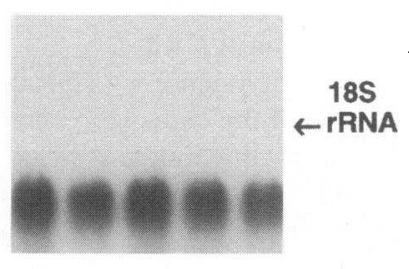

- 1h $4 h 6 h 24 h$

$\begin{array}{lllll}0 & \underline{0} & 0 & 0 & 0\end{array}$
Figure 9. Northern blot analysis of chromogranin A and cyclophilin mRNA levels. Neuroendocrine (PC12) and control (NIH3T3) cells were exposed to dibutyryl cAMP ( $1 \mathrm{mM}$ ) for $1,4,6$, or $24 \mathrm{~h}$. Total RNA $(10 \mu \mathrm{g})$ from these cells was size fractionated on a denaturing agarose gel and sequentially hybridized with specific cDNA probes for chromogranin A and cyclophilin. The mobility of the $18 \mathrm{~S}$ ribosomal RNA is indicated on the right. Relative chromogranin A mRNA levels were normalized to cyclophilin mRNA and expressed as fold induction by cAMP. A representative experiment is shown. 


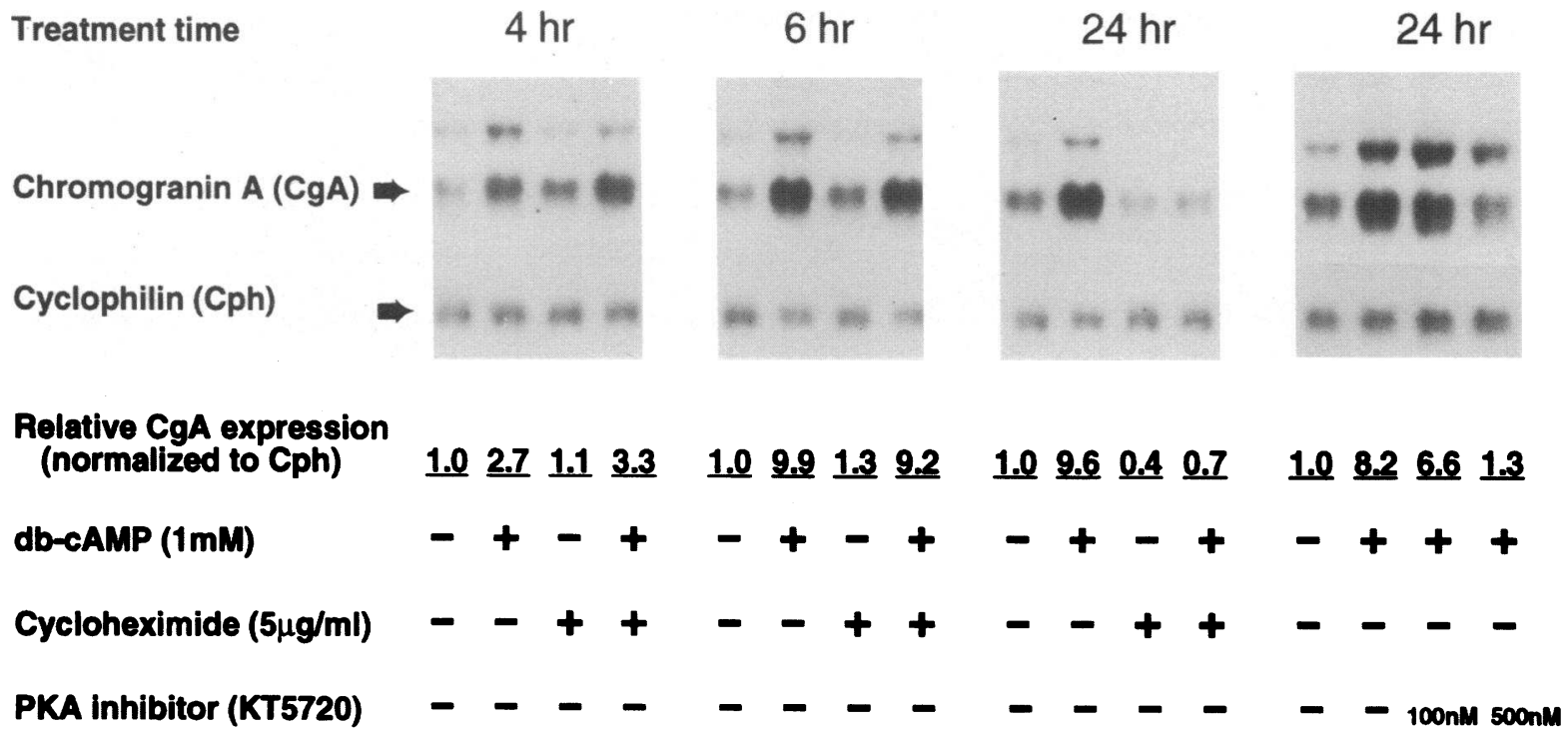

Figure 10. Time course of chromogranin A mRNA induction by cAMP and the role of new protein synthesis and protein kinase A in the induction. Neuroendocrine PC12 chromaffin cells were exposed to dibutyryl cAMP ( $1 \mathrm{mM}$ ) for 4, 6, or $24 \mathrm{~h}$, either alone or in combination with either the protein synthesis (translation) inhibitor cycloheximide $(5 \mu \mathrm{g} / \mathrm{ml})$ or the protein kinase A inhibitor $\mathrm{KT}^{2} 720\left(10^{-7}\right.$ or $\left.5 \times 10^{-7} \mathrm{M}\right)$. Chromogranin A and cyclophilin mRNA levels were determined, normalized, and expressed as described in the legend to Fig. 9. A representative experiment is shown.

the endogenous chromogranin A gene by cAMP (Fig. 9; 24-h stimulation). Similarly, the chromogranin A gene is inducible by the adenylyl cyclase activator forskolin in bovine chromaffin cells (6), though the forskolin response in PC12 cells may be blunted (25).

A comparison of mouse chromogranin A's proximal promoter region with the rat, bovine, and human promoters (Fig. 12) shows high conservation of the overall promoter structure, including the TATA and CRE homologies (5-7). The mouse, rat, bovine, and human promoters all contain a CRE box 1842 bp upstream of the TATA box (Fig. 12). The bovine (6) and human (7) chromogranin A genes contain perfect consensus (10) CREs (TGACGTCA), similar to that in the M14 mutation (Figs. 1 and 3 ) generated for this study. The mouse (5) and rat (5) genes differ from the consensus at 1 nucleotide (TGACGTAA; difference underlined).

This conservation of the CRE site and TATA box is also seen in two other members of the family of chromogranin/ secretogranin proteins, chromogranin B and secretogranin II (chromogranin C) $(8,9)$ (Fig. 12). The chromogranin/secretogranin promoters show very little homology outside of the TATA and CRE sequences.

CRE sites have been identified in many neuroendocrinespecific gene promoters. cAMP stimulates the activity of a number of neuroendocrine-specific genes, including chromogranin B $(26,27)$ and secretogranin II $(26-28)$, tyrosine hydroxylase (29), phenylethanolamine- $N$-methyltransferase (30), dopamine $\beta$-hydroxylase (DBH) $(31,34)$, anterior pituitary glyco-

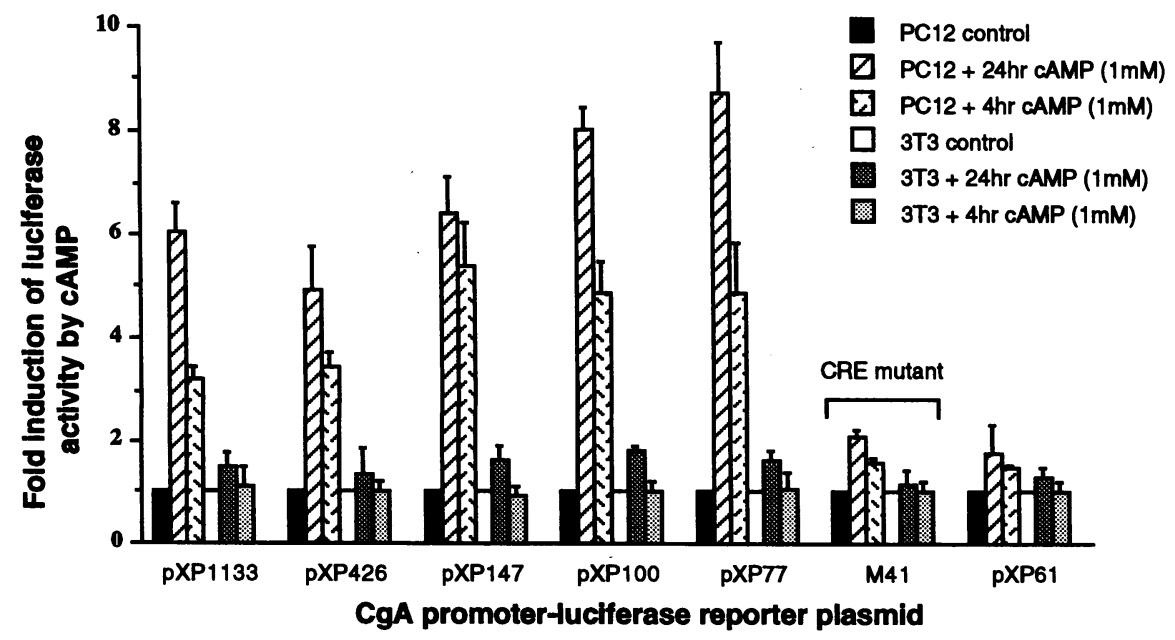

Figure 11. Induction of activity of transfected chromogranin A promoter/reporter plasmids by cAMP. Chromogranin A promoter progressive 5 ' deletion mutant/luciferase reporter plasmids (pXP1133, pXP426, pXP147, pXP100, pXP77, or pXP61), or a CRE box site-directed mutant plasmid (mutant M41 [Figs. 1 and ]; promoter 5 ' length to $-77 \mathrm{bp}$; original TGACGTAA CRE altered to TGA-GTAA) was transfected into neuroendocrine (PC12) or control (NIH3T3) cells. The transfected cells were treated with either vehicle (control) or dibutyryl cAMP ( $1 \mathrm{mM}$ ) for 4 or $24 \mathrm{~h}$, and processed for luciferase reporter and protein assay. The results are expressed as fold induction by cAMP of luciferase activity over the respective control. In this experiment, since each cAMP stimulation had its own control (the same promoter fragment, unstimulated by cAMP), the ratios were computed simply as stimulated/unstimulated. Hence, no CMV-lacZ internal control was required. This circumvents the potential pitfall of cAMP responsiveness of the usual transfection efficiency control plasmid (CMV-lacZ). 


\section{1) Interspecies allgnment of CgA promoter}

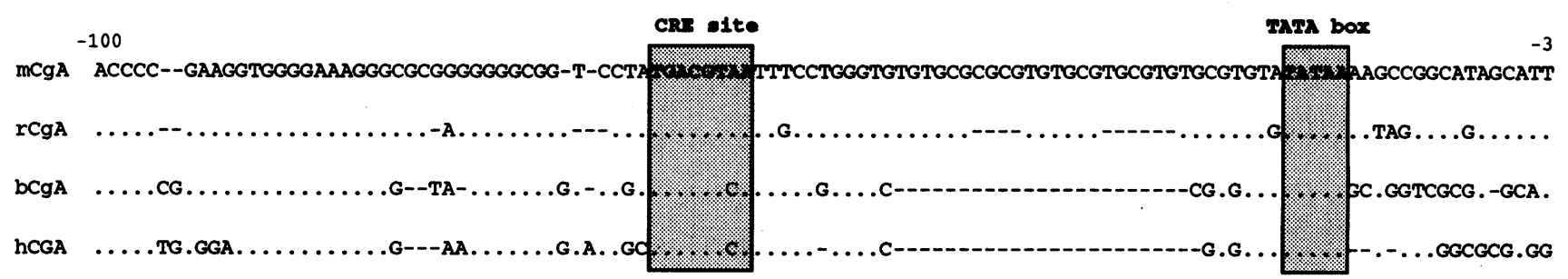

\section{2) Allgnment with related mouse chromogranin/secretogranin promoter}

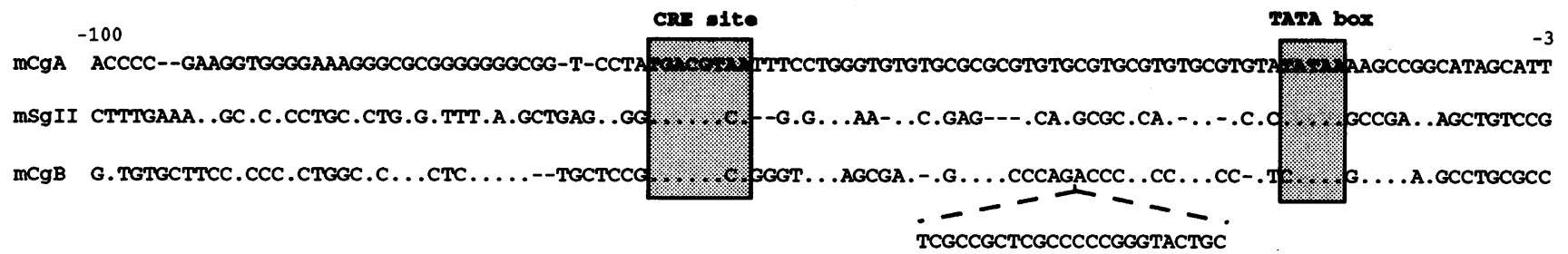

Figure 12. Alignment of chromogranin/secretogranin proximal promoter sequences. (1) Interspecies (mouse $[m C g A]$, rat $[r C g A]$, human $[h C g A]$, and bovine $[b C g A]$ ) alignment of chromogranin A proximal promoters reveals a high degree of conservation of the overall promoter structure, with sequence similarities not limited to the CRE site and TATA box. The numbering refers to base pairs upstream ( $\left.5^{\prime}\right)$ of the transcriptional start (cap) site for each promoter. Dots indicate homology (conserved bases) with the mouse chromogranin A promoter. Dashes indicate a space (gap) in the sequence. (2) When the mouse chromogranin $\mathrm{A}(\mathrm{mCgA})$ proximal promoter is aligned with mouse promoters of other members of the chromogranin/secretogranin protein family (chromogranin $\mathrm{B}[\mathrm{mCgB}]$ and secretogranin $\mathrm{II}[\mathrm{mSgII}]$ ), the only regions with consistent, conserved homology in all three promoters are the CRE site and the TATA box. A proximal 24-bp insertion in the mouse chromogranin B promoter (as compared with the shorter chromogranin A or secretogranin II promoter in this region) is shown.

protein hormone $\alpha$ subunit $(32,34)$, and renin $(33,36)$, although not all of these cAMP effects have been clearly shown to be transcriptional $(26-28,30,33)$. Furthermore, CRE sites have been implicated in the cell type-specific expression of the DBH (34), glycoprotein hormone $\alpha$ subunit (35), and renin (36) genes. Mutation of CRE sites in those genes causes a significant decline in promoter activity in the appropriate cell type, similar to the results presented here for the chromogranin A promoter (Figs. 3 and 4). DNase I-hypersensitive sites have been observed over the CRE site in the $\mathrm{DBH}$ proximal promoter in chromatin from noradrenergic human neuroblastoma cells but not HeLa epithelioid carcinoma cells, suggesting that the CRE site is a cis-acting element specifically recognized by trans-acting factors in vivo (34).

However, it should be noted that not all endocrine-specific genes contain CRE consensus transcriptional activation promoter sequences. For example, the growth hormone promoter does not respond directly to cAMP; instead, its transactivator Pit-1 (GHF-1) transduces the cAMP signal of hypothalamic growth hormone-releasing factor in anterior pituitary somatotropes (37). Therefore, the presence of a CRE consensus is not entirely necessary to guarantee neuroendocrine cell typespecific expression, and additional (non-CRE) mechanisms (such as Pit-1) for maintaining such expression must exist in at least some neuroendocrine promoters.

Promoters of non-endocrine-specific genes, such as fibronectin, may also contain functional CRE sites $(38-40)$, so the presence of a CRE cannot be entirely specific for neuroendocrine tissue-specific expression, but may be necessary in the context of certain promoters, such as those of the chromogranin/ secretogranins (Fig. 12).

If the CRE site does mediate the tissue-specific expression of the chromogranin/secretogranin neuroendocrine genes, then how is this accomplished at the molecular level? A single copy of the chromogranin A CRE increased the activity of a neutral, heterologous TK promoter 7-10-fold in PC12 and AtT20 cells, though not in NIH3T3 fibroblasts (Fig. 8). This increase in basal promoter activity by the CRE in neuroendocrine cells is far less than the degree of neuroendocrine selectivity of chromogranin A transfected promoter strength observed with the long 4.8-kp chromogranin A promoter (5) in AtT20 cells (23fold more active than in NIH3T3 cells) or PC12 cells (59-fold more active than in NIH3T3 cells). The endogenous chromogranin A gene shows even more exquisite cell type specificity, since chromogranin A mRNA is undetectable in NIH3T3 fibroblasts (Fig. 9). Thus the chromogranin A promoter CRE site, through completely necessary for neuroendocrine-specific expression of the gene, is not completely sufficient to account fully for the highly selective pattern of expression of the gene in vivo. The endogenous chromogranin A gene promoter, as well as the transfected long promoters, must therefore contain additional elements that accentuate the effect of the CRE site. For example, site-directed mutations in the vicinity just upstream of the CRE site (Fig. 3), such as those in the Ap2/ Egr1/Sp1 consensus matches (mutations M6-M9), as well as mutations just downstream of the CRE site (mutations M16M19), also had a somewhat more pronounced effect in neuroendocrine cells than a fibroblasts. The distant $(-2.2$ to $-4.8 \mathrm{~kb})$ positive domain in the chromogranin A promoter also specifically activates gene expression in neuroendocrine cells (5).

In contrast to the completely absent expression of the endogenous chromogranin A gene in NIH3T3 fibroblasts (Fig. 9), some basal expression of the transfected chromogranin A promoter is observed in these same ells (Fig. 9). This discrepancy 
is commonly observed in transient transfection analyses of promoter strength; many studies have reported higher basal promoter activity after acute introduction of plasmids, as compared with table transfection and expression of a plasmid integrated into cellular genomic DNA. Differences in expression of the same promoter sequences in the two circumstances may be referable to the relative lack of nucleosomal or other chromatin structure in acutely transfected, still episomal plasmids $(41,43)$.

Although many transcription factors can recognize a CRE in vitro, the best characterized protein that recognizes this sequence in vivo is the CRE-binding protein CREB $(23,43)$. Electrophoretic mobility shift assays, combined with supershift assays using an antibody to CREB, demonstrated that CREB is present in nuclei from both AtT20 and NIH3T3 cells and can bind to the chromogranin A CRE (Fig. 7).

If CREB is present in both endocrine and nonendocrine cells and can bind to the CRE in each, how then is tissue specificity of expression achieved? Modulation of the activity of CREB on the chromogranin A promoter in NIH3T3 fibroblasts could occur by several possible mechanisms $(23,43-$ 47), including changes in CREB phosphorylation, competition for CREs by repressor factors or different transactivators, binding of CREB by a repressive adaptor molecule, heterodimerization of CREB with another bZIP family protein, or relative lack of a CREB coactivator (48). The polyclonal antibody used in our supershift assay (Fig. 7) was raised against a synthetic peptide spanning amino acids 121-159 of rat CREB, a region containing the domain that is phosphorylated by protein kinase A (Ser-133) during CREB activation $(12,43)$. This antibody may recognize other related proteins with partial sequence homology in this kinase-inducible domain, such as the CRE modulator protein, CREM $(23,43,44)$.

Based on the anti-CREB supershift data (Fig. 7), CREB appears to be at least one component of the AtT20 CRE complex. A complex of similar mobility is observed in NIH3T3 cell extracts; however, when anti-CREB antibody supershifts the NIH3T3 complex, it is possible to distinguish two complexes not seen in the anti-CREB-supershifted AtT20 extract: one NIH3T3 CRE complex is not supershifted by the antibody and therefore does not contain the kinase-inducible domain epitope; another NIH3T3 CRE complex is supershifted, but to a greater (faster) mobility than the AtT20 complex. The presence of CREB in two distinct supershifted NIH3T3 CRE complexes raises the possibility that CREB is forming heterodimers with other factors.

An attractive possibility is that such heterodimeric NIH3T3 CRE complexes may inhibit stimulation by CREB $(23,43)$. CREB is a widely distributed transcription factor belonging to the bZIP superfamily (23). Proteins of this family bind to DNA as dimers, and dimerization is mediated by the leucine-zipper motif (23). CREB has been shown not only to homodimerize, but also to heterodimerize with bZIP family members (23) such as ATF1 and CREM; CREB also binds to the CREB-binding protein, which may bridge CREB to the transcriptional initiation complex (47). The relative ratios of various CREB binding partners may have important consequences for transcriptional stimulation through the CRE motif $(23,43,45)$. The CREM family of proteins can function in both a positive and negative sense, depending on alternative splicing and alternative promoter usage (45). CREM family members are present in AtT20 and PC12 cells but not in NIH3T3 cells (44) and so are unlikely to be components of the additional CRE complexes (Fig. 7) found in NIH3T3 cells. Heterodimers of CREB with ATF1 or CREB-binding protein still function in a positive sense, since they can mediate a cAMP response $(23,43)$. Perhaps there are other as yet unidentified CREB heterodimers in the NIH3T3 nuclear milieu, which function to negate CREB's stimulatory action on the CRE box in such cells. This possibility may explain why there is no induction of the endogenous chromogranin A gene after cAMP in NIH3T3 cells (Fig. 9), in spite of the presence of CREB in these cells $(23,43,46)$. It should be noted that other groups have observed cAMP stimulation of transfected gene expression in NIH3T3 cells, but only on artificial promoters containing multiple CRE sites and never on single CREs $(49,50)$.

An NIH3T3 complex with the CRE oligonucleotide persisted even when the chromogranin A CRE sequence (TGACGTAA) was mutated to TGA-GTAA (Fig. 7, lane 12), though the complex no longer occurred in AtT20 cells (Fig. 7, lane 11). It should be noted that the TGA-GTAA mutation (also used in mutants M12 [Figs. 1 and 3] and M41 [Figs. 1 and 4] as well as in the inactive TK transfer experiment [Fig. 8]) not only inactivates the response of this element to cAMP (Fig. 11), but also converts this element into a consensus match (TGANTMA; IUPAC code) for an Ap1 site (24).

In conclusion, the CRE site in the chromogranin A proximal promoter plays a crucial, indeed indispensable role in tissuespecific expression of the chromogranin A gene. In our model, CREB binds to the CRE in both neuroendocrine and fibroblast cells, but its activity may be inhibited in the fibroblast cells by other factors that can also recognize this element. IN neuroendocrine cells, CREB binding alone causes an elevation in the basal transcription of the chromogranin A promoter, which can be further increased by cAMP treatment or the presence of additional tissue-specific elements further upstream.

\section{Acknowledgments}

We appreciate the gift of reagents (including CREB and anti-CREB antiserum) and the suggestions from Paul Brindle and Marc Montminy of the Salk Institute (San Diego, CA).

This study was supported by the Department of Veterans Affairs, the National Institutes of Health (R01-HL46366 and T32-DK07671), and the American Heart Association.

\section{References}

1. O'Connor, D. T. 1983. Chromogranin: widespread immunoreactivity in polypeptide hormone producing tissues and in serum. Regul. Pept. 6:263-280.

2. O'Connor, D. T., D. G. Burton, and L. J. Deftos. 1983. Chromogranin A immunohistology reveals its universal occurrence in normal polypeptide hormone producing endocrine glands. Life Sci. 33:1657-1663.

3. Huttner, W. B., H. H. Gerdes, and P. Rosa. 1991. Chromogranins/secretogranins - widespread constituents of the secretory granule matrix in endocrine cells and neurons. In Markers for Neural and Endocrine Cells. M. Gratzl and K. Langley, editors. VCH Verlagsgesellschaft, Weinheim, Germany. 93-131.

4. Weiler, R., R. Fischer-Colbrie, K. W. Schmid, H. Feichtinger, G. Bussolati, L. Grimelius, K. Krisch, H. Kerl, D. T. O'Connor, and H. Winkler. 1988. Immunological studies on the occurrence and properties of chromogranin A and B and secretogranin II in endocrine tumors. Am. J. Surg. Pathol. 12:877-884.

5. Wu, H. J., D. J. Rozansky, N. L. G. Webster, and D. T. O'Connor. 1994 Cell type-specific gene expression in the neuroendocrine system: a neuroendocrine-specific regulatory element in the promoter of chromogranin $\mathrm{A}$, a ubiquitous secretory granule core protein. J. Clin. Invest. 94:118-129.

6. Iacangelo, A. L., M. Grimes, and L. E. Eiden. 1991. The bovine chromogranin A gene: structure basis for hormone regulation and generation of biologically active peptides. Mol. Endocrinol. 5:1651-1660.

7. Mouland, A. J., S. Bevan, J. H. White, and G. N. Hendy. 1994. Human chromogranin A gene: molecular cloning, structural analysis, and neuroendocrine cell-specific expression. J. Biol. Chem. 269:6918-6926. 
8. Pohl, T. M., E. Phillips, K. Song, H.-H. Gerdes, W. B. Huttner, and U. Ruther. 1990. The organisation of the mouse chromogranin B (secretogranin I) gene. FEBS (Fed. Eur. Biochem. Soc.) Lett. 262:219-224.

9. Schimmel, A., O. Braunling, U. Ruther, W. B. Huttner, and H.-H. Gerdes. 1992. The organisation of the mouse secretogranin II gene. FEBS (Fed. Eur. Biochem. Soc.) Lett. 314:375-380.

10. Montminy, M. R., K. A. Sevarino, J. A. Wagner, G. Mandel, and R. H. Goodman. 1986. Identification of a cyclic-AMP-responsive element within the rat somatostatin gene. Proc. Natl. Acad. Sci. USA. 83:6682-6686.

11. Kase, H., K. Iwahashi, S. Nakanishi, Y. Matsuda, K. Yamada, M. Takahashi, C. Murakata, A. Sato, and M. Kaneko. 1987. K-252 compounds, novel and potent inhibitors of protein kinase $\mathrm{C}$ and cyclic nucleotide-dependent protein kinases. Biochem. Biophys. Res. Commun. 142:436-440.

12. Yamamoto, K. K., G. A. Gonzalez, P. Menzel, J. Rivier, and M. R. Montminy. 1990. Characterization of a bipartite activator domain in transcription factor CREB. Cell. 60:61-617.

13. Nordeen, S. K. 1988. Luciferase reporter gene vectors for analysis of promoters and enhancers. BioTechniques. 6:454-456.

14. Sanger, F., S. Nicklen, and A. R. Coulson. 1977. DNA sequencing with chain-terminating inhibitors. Proc. Natl. Acad. Sci. USA. 74:5463-5467.

15. Greene, L. A., and A. S. Tischler. 1976. Establishment of a noradrenergic clonal line of rat adrenal pheochromocytoma cells which respond to nerve growth factor. Proc. Natl. Acad. Sci. USA. 73:2424-2428.

16. Dickerson, I. M., and R. E. Mains. 1990. Cell-type specific posttranslational processing of peptides by different pituitary cell lines. Endocrinology. 127:133-140.

17. Sambrook, J., E. F. Fritsch, and T. Maniatis. 1989. Molecular Cloning A Laboratory Manual. Second edition. Cold Spring Harbor Laboratory, Cold Spring Harbor, NY.

18. DeWet, J. R., K. V. Wood, M. DeLuca, D. R. Helinski, and S. Subramani. 1987. Firefly luciferase gene: structure and expression in mammalian cells. Mol. Cell. Biol. 7:725-737.

19. Ausubel, F. M., R. Brent, R. E. Kingston, D. D. Moore, J. G. Seidman, J. A. Smith, and K. Struhl, editors. 1987-1993. Current Protocols in Molecular Biology. Greene and John Wiley \& Sons, Inc., New York.

20. Rozansky, D. J., H. J. Wu, K. Tang, R. J. Parmer, and D. T. O'Connor. 1994. Glucocorticoid activation of chromogranin A gene expression. Identification and characterization of a novel glucocorticoid response element. J. Clin. Invest. 94:2357-2368.

21. Wu, H. J., D. J. Rozansky, R. J. Parmer, B. M. Gill, and D. T. O'Connor 1991. Structure and function of the chromogranin A gene: clues to evolution and tissue-specific expression. J. Biol. Chem. 266:13130-13134.

22. Hasel, K. W., and J. G. Sutcliffe. 1990. Nucleotide sequence of a cDNA coding for mouse cyclophilin. Nucleic Acids Res. 18:4019.

23. Hurst, H. C. 1994. Transcription factors 1: bZIP proteins. Protein Profile $1 ; 123-152$.

24. Lee, W. P. Mitchell, and R. Tjian. 1987. Purified transcription factor AP1 interacts with TPA-inducible enhancer elements. Cell. 49:741-752.

25. Laslop, A., C. Tschernitz, and C. Eiter. 1994. Biosynthesis of proteins of large dense-core vesicles in rat PC12 cells: regulation by forskolin and phorbol ester. Neuroscience. 59:477-485.

26. Thompson, M. E., W. E. Zimmer, L. B. Wear, L. A. MacMillan, W. J. Thompson, W. B. Huttner, H. Hidaka, and J. G. Scammell. 1992. Differentia regulation of chromogranin B/secretogranin I and secretogranin II by forskolin in PC12 cells. Brain Res. Mol. Brain Res. 12:195-202.

27. Thompson, M. E., D. L. Valentine, S. J. Strada, J. A., Wagner, and J. G. Scammell. 1994. Transcriptional regulation of secretogranin II and chromogranin B by cyclic AMP in a rat pheochromocytoma cell line. Mol. Pharmacol. 46:880889.

28. Fischer-Colbrie, R., J. Gutierrez, C. M. Hsu, A. Iacangelo, and L. E. Eiden. 1990. Sequence analysis, tissue distribution and regulation by cell depolarization, and second messengers of bovine secretogranin II (chromogranin C) mRNA. J. Biol. Chem. 265:9208-9213.

29. Kim, K.-S., C. Tinti, B. Song, J. F. Cubells, and T. H. Joh. 1994. Cyclic AMP-dependent protein kinase regulates basal and cyclic AMP-stimulated but not phorbol ester-stimulated transcription of the tyrosine hydroxylase gene. $J$. Neurochem. 63:834-842.

30. Wan, D. C., P. D. Marley, and B. G. Livett. 1991. Coordinate and differential regulation of proenkephalin A and PNMT mRNA expression in cultured bovine adrenal chromaffin cells: responses to cAMP elevation and phorbol esters. Brain Res. Mol. Brain Res. 9:135-142.

31. McMahon, A., and E. L. Sabban. 1992. Regulation of expression of dopamine beta-hydroxylase in PC12 cell by glucocorticoids and cyclic AMP analogues. J. Neurochem. 59:2040-2047.

32. Hausebkeder, D. J., M. Yasin, and J. C. Marshall. 1992. Enhanced effectiveness of pulsatile $3^{\prime}, 5^{\prime}$-cyclic adenosine monophosphate in stimulating prolactin and alpha-subunit gene expression. Endocrinology. 131:3027-3033.

33. Chen, M., J. Schnermann, A. M. Smart, F. C. Brosius, P. D. Killen, and J. P. Briggs. 1993. Cyclic AMP selectivity increases renin mRNA stability in cultured juxtaglomerular granular cells. J. Biol. Chem. 268:24138-24144.

34. Ishiguro, H., K. T. Kim, T. H. Johs, and K. S. Kim. 1993. Neuron-specific expression of the human dopamine beta-hydroxylase gene requires both the cAMP-response element and a silencer region. J. Biol. Chem. 268:17987-17994.

35. Steger, D. J., J. H. Hecht, and P. L. Mellon. 1994. GATA-binding proteins regulate the human gonadotropin alpha-subunit gene in the placenta and pituitary gland. Mol. Cell. Biol. 14:5592-5602.

36. Horiuchi, M., N. Nakamura, S. S. Tang, G. Barrett, and V. J. Dzau. 1991. Molecular mechanism of tissue-specific regulation of mouse renin gene expression by cAMP. Identification of an inhibitory protein that binds nuclear transcriptional factor. J. Biol. Chem. 266:16247-16254.

37. Thiell, L. E., and M. Karin. 1993. Transcriptional control of GH expression and anterior pituitary development. Endocr. Rev. 14:670-689.

38. Muro, A. F., V. A. Bernath, and A. R. Kornblihtt. 1992. Interaction of the -170 cyclic AMP response element with the adjacent CCAAT box in the human fibronectin gene promoter. J. Biol. Chem. 267:12767-12774.

39. Bowlus, C. L., J. J. McQuillan, and D. C. Dean. 1991. Characterization of three different elements in the 5'-flanking region of the fibronectin gene which mediate a transcriptional response to cAMP. J. Biol. Chem. 226:1122-1127.

40. Dean, D. C., J. J. McQuillan, and S. Weintraub. 1990. Serum stimulation of fibronectin gene expression appears to result from rapid serum-induced binding of nuclear proteins to cAMP response element. J. Biol. Chem. 265:3522-3527.

41. Laybourn, P. J., and J. T. Kadonaga. 1991. Role of nucleosomal cores and histone $\mathrm{H1}$ in regulation of transcription by RNA polymerase II. Science (Wash. DC). 254:238-245.

42. Smith, C. L., T. K. Archer, G. Hamlin-Green, and G. L. Hager. 1993. Newly expressed progesterone receptor cannot activate stable, replicated mouse mammary tumour virus templates but acquires transactivation potential upon continuous expression. Proc. Natl. Acad. Sci. USA. 90:11202-11206.

43. Brindle, P. K., and M. R. Montminy. 1992. The CREB family of transcription activators. Curr. Opin. Gene Dev. 2:199-204.

44. Brindle, P. K., L. Steve, and M. Montminy. 1993. Protein-kinase-A dependent activator in transcription factor CREB reveals new role for CREM repressors. Nature (Lond.). 364:821-824.

45. de Groot, R. P., L. M. Ballou, and P. Sassone-Corsi. 1994. Positive regulation of the cAMP-responsive activator CREM by the p70 S6 kinase: an alternative route to nitrogen-induced gene expression. Cell. 79:81-91.

46. Molina, C. A., N. S. Foulkes, E. Lalli, and P. Sassone-Corsi. 1993. Inducibility and negative autoregulation of CREM: an alternative promoter directs the expression of ICER, an early response repressor. Cell. 75:875-886.

47. Chrivia, J. C., R. P. S. Kwok, N. Lamb, M. Hagiwara, M. R. Montminy, and R. H. Goodman. 1993. Phosphorylated CREB binds specifically to the nuclear protein CBP. Nature (Lond.). 365:855-859.

48. Nordheim, A. 1994. Transcription factors. CREB takes CBP to tango. Nature (Lond.). 370:177-178.

49. Alberts, A. S., J. Arias, M. Hagiwara, M. R. Montminy, and J. R. Feramisco. 1994. Recombinant cyclic AMP response element binding protein (CREB) phosphorylated on Ser-133 is transcriptionally active upon its introduction into fibroblast nuclei. J. Biol. Chem. 269:7623-7630.

50. Alberts, A. S., M. Montminy, S. Shenolikar, and J. R. Feramisco. 1994 Expression of a peptide inhibitor of protein phosphatase 1 increases phosphorylation and activity of CREB in NIH 3T3 fibroblasts. Mol. Cell. Biol. 14:4398-4407. 